\title{
Strength Characteristics and Empirical Criterion of Dry and Saturated Sandstone Subjected to Compression Test
}

\author{
Yunfei Wang ${ }^{1,2}$, Shuren Wang ${ }^{1,2,3, *}$, Zhen $\mathrm{Li}^{2}$ and Huazhe Jiao ${ }^{2}$ \\ ${ }^{1}$ International Joint Research Laboratory of Henan Province for Underground Space Development and Disaster Prevention, Henan \\ Polytechnic University, Jiaozuo 454003, China \\ ${ }^{2}$ School of Civil Engineering, Henan Polytechnic University, Jiaozuo 454003, China \\ ${ }^{3}$ School of Minerals and Energy Resources Engineering, University of New South Wales, Sydney, NSW 2052, Australia
}

Received 29 December 2019; Accepted 23 March 2020

\begin{abstract}
Determining the strength of rock mass is the key to the stability analysis and support design of underground engineering, which is affected by groundwater and softening characteristics of different lithology. Taking the red sandstone under the dry and saturated state as the research object, the uniaxial and triaxial compressive tests on RMT (rock mechanics test) device were carried out, the strength and deformation difference of the dry and saturated red sandstone were analyzed. Results show that the saturated red sandstone displays the strength degradation and softening effect under uniaxial compressive test and lower confining pressure conditions, and which shows the linear elastic weaken characteristics. When the confining pressure is greater than $20 \mathrm{MPa}$, the strength degradation and softening effect tend to a certain value. The uniaxial compressive strength degradation rate is 1.92 times of that under high confining pressure. The degradation of cohesion of the saturated red sandstone is obvious, but the degradation of the internal friction angle is little. The saturated red sandstone reduces its brittleness, makes the fracture surface regular, and the fracture angle is generally smaller than that under the dry state. Taking $30 \mathrm{MPa}$ as the turning confining pressure, the polyline strength criterion was established, and the three-dimension strength criterion of the red sandstone under the dry and saturated state was constructed. The obtained conclusions in the study can provide the reference to the similar engineering.
\end{abstract}

Keywords: Red sandstone, Dry and saturated state, Strength criterion, Deformation characteristic

\section{Introduction}

For the deep rock mass, the physical and chemical reaction of groundwater and rock can change the micro structure of the rock mass, with the development of the micro cracks, which often causes the gradual deterioration of the mechanical properties of the rock mass, reduces the strength and causes the instability and failure of the engineering surrounding rock. In essence, the failure of the rock mass is the macro results of the continuous development of the internal defect expansion and coalescence. The action of water is the main influencing factor of the deformation and failure of the surrounding rock in the underground engineering.

With the development of underground space utilization, the safety of the rock engineering becomes more and more prominent. Mastering the softening mechanism of the rock is the basis for controlling the stability of the underground engineering under groundwater conditions. In general, the actual geological conditions are complex, the deformation and strength degradation effects of different lithology are quite different under different geological conditions. Although lots of researches on the strength and deformation degradation of the rock mass, because of the differences in lithology and geological conditions, if the obtained results were directly used in different engineering, it may cause too high or too low estimation of the strength and deformation

*E-mail address: w_sr88@163.com

ISSN: 1791-2377 @ 2020 School of Science, IHU. All rights reserved.

doi:10.25103/jestr.132.16 of the rock mass. Therefore, it is necessary to reasonably determine the parameters of the rock mass, and put forward the strength design formula suitable for the rock mass.

Since the saturated condition plays a key role in the deformation and stability of the underground engineering, which may lead to the large deformation of the surrounding rock, seriously threaten the long-term stability of the underground engineering. So, it is of great engineering significance to analyze the strength characteristics and empirical criterion of the dry and saturated rock.

\section{Start of the Art}

At present, lots of researches have been conducted on the deformation and strength degradation of the rock mass under dry and saturated states and some useful results are obtained. For examples, Wang et al. studied the influences of different water contents on the mechanical properties of sandstone [1]. Deng et al. analyzed the influences of dry and wet cycles on the micro structure and strength degradation of the sandstone on the reservoir bank, and they found that the strength and deformation characteristics of the sandstone were weakened by the water [2-3]. Zhu et al. researched the influence of water on the strength characteristics of marble, they found that the normalized fracture strength decreased and the normalized damage strength increased under the saturated state [4]. Mei et al. investigated the time-dependent characteristics of the crack propagation and the failure mode of the rock, they found that the saturated water made the soft rock ductility characteristics obvious and the internal 
structure of the rock gradually became loose and porous [58]. The weakening of the macroscopic mechanical properties was closely related to the changes in the microstructures of the rocks. The water-rock interaction changed the size, shape and porosity of the rock pores and affected its mechanical properties [9]. Wong et al. pointed out that the water weakening degree of different rocks was different due to the difference of the geological lithology. The water-weakening degree of the rock properties depended on the porosity as well as the mineralogy, especially the proportion of the quartz and swelling clays [10-12].

The microcrack growth and softening difference of different rocks were analyzed in detail in the previous studies. However, the research on the quantitative expression of deformation and strength degradation in saturated rocks needs to be further improved. Hashiba \& Fukuiet analyzed 42 sets of rock test data, and they found that water and confining pressure have little effect on the strength of the low strength rock with the increase of the loading rate [13]. Based on the damage friction coupling analysis, Zhang at al. studied the softening characteristics and strength degradation law, and they found that the water absorption was negatively related to the uniaxial compressive strength and elastic modulus of chlorite amphibolite [14-15]. He et al. established a fractal model of rock strength, which could well explain the change of rock strength with the equivalent diameter of particles [16]. The influence of confining pressure and water on the strength and energy evolution of sandstone under stepwise loading and unloading were also studied [17-18]. Cui et al. conducted numerical experiments on the jointed rock mass to study the rock mechanical characteristics [19-20]. Based on 106 sandstones samples from three locations in Malaysia, Liang et al. conducted the simple regression analysis to predict the uniaxial compressive strength [21]. Li \& Wang pointed out that the strength of the rock decreased rapidly with increase of water content at low saturation levels, but the strength of the rock decreased insignificant with increase of water content at high saturation levels, and they established the analytical solution for the normalized uniaxial compressive strength of rock with different saturation states [22]. Mohamad et al. constructed some models to estimate the rock strength [23-24]. Zou \& Jiao studied the strength and damage difference of hard and soft rocks under multi- and single-step triaxial compression tests [25]. Zhang et al. used Lode's angle dependent function to express the effect of the intermediate principle stress, and they proposed a new true triaxial criterion by combining the meridian and deviatoric plane function [26].

The above mentioned studies were mainly the classical strength criteria and prediction model based on the program algorithm and multi parameters strength criteria proposed by scholars in terms of strength change law. However, the accuracy of the classical criterion is low, and its parameters are not easy to be determined accurately in other multiparameters strength criteria. Based on the compression tests on the dry and saturated sandstones, the deformation and strength degradation of the red sandstone were obtained. The formula of the polyline strength criterion was proposed, which was easy to determine its parameters and this criterion had the good engineering application.

The rest of this study is organized as follows. Section 3 describes samples preparation, test device and research method. Section 4 gives the results and discussion. Finally, the conclusions are summarized in section 5 .

\section{Methodology}

\subsection{Samples preparation}

The red sandstone was taken from Neijiang City, Sichuan Province, China, and was processed into cylindrical standard samples with the size of $\phi 50 \mathrm{~mm} \times 100 \mathrm{~mm}$ in strict accordance with the standard of the international society for rock mechanics. To ensure the homogeneity of the rock samples, as shown in Fig. 1, the samples were selected by the longitudinal wave velocity and the mean velocity of the red sandstone under dry state is $2.948 \mathrm{~km} / \mathrm{s}$. The density of the red sandstone is 2401 and $2472 \mathrm{~kg} / \mathrm{m}^{3}$ under the dry and saturated states, respectively. The homogeneous samples under dry state were divided into two batches, one was tested directly, and the other was tested after being saturated with water.

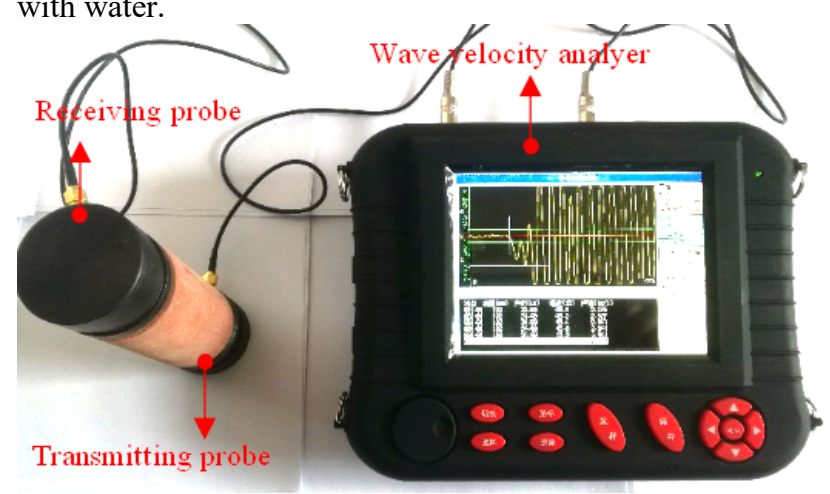

Fig. 1. Red sandstone samples were selected by longitudinal wave velocity.

\subsection{Device and method}

The rock mechanics test RMT-150B was used to carry out the uniaxial and triaxial compressive test of the red sandstone under dry and saturated states. The sensor with $1000 \mathrm{kN}$ force was used to measure the vertical load and 5 $\mathrm{mm}$ displacement sensor was used to measure the vertical deformation of the samples. Using displacement control loading method, the axial loading rate was set $0.002 \mathrm{~mm} / \mathrm{s}$, and the confining pressure control rate was $0.10 \mathrm{MPa} / \mathrm{s}$.

The uniaxial compressive test was carried out at the loading rate of $0.002 \mathrm{~mm} / \mathrm{s}$ till the sample was damaged. In the test, the hydrostatic pressure was applied to the predetermined confining pressure along the isoclinic line, and then the confining pressure was controlled by servo, and the axial force was applied till the sample was damaged. Three group samples were taken for the uniaxial compressive test of red sandstone under dry and saturated states. The confining pressure of triaxial compressive test was 5, 10, 20, 30, and $40 \mathrm{MPa}$, respectively, as shown in Fig. 2.

The dry and saturated uniaxial compressive tests were carried out with three group samples, respectively. The test procedure is as following:

(1) Samples were selected by the longitudinal wave velocity and appearance characteristics.

(2) Dry samples: the samples were put into the drying oven, setting the temperature at $105^{\circ} \mathrm{C}$ and drying for $24 \mathrm{~h}$.

(3) Saturated samples: some dry samples were put into the water, measuring the weight of the samples every other day till the weight of each sample did not change.

(4) The uniaxial and triaxial compressive tests were carried out on the rock mechanics test system, the loading rate was $0.002 \mathrm{~mm} / \mathrm{s}$, and acoustic emission monitoring was carried out at the same time. 


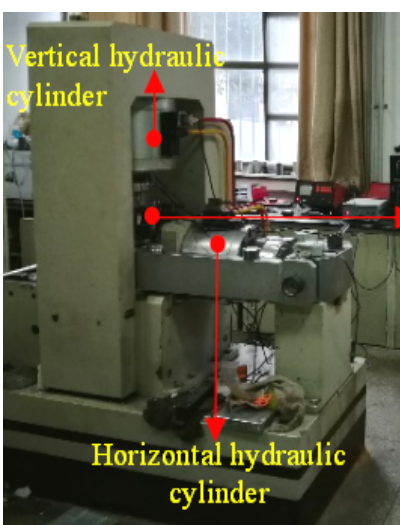

(a) Test device

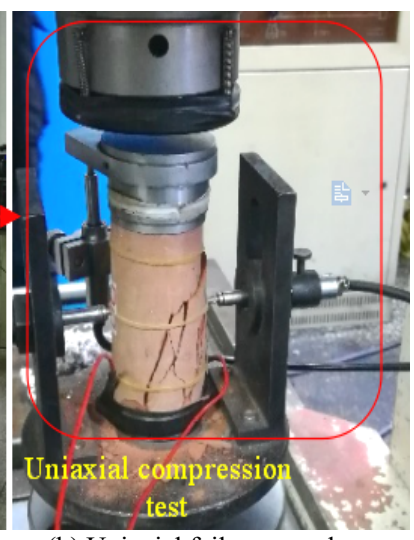

(b) Uniaxial failure sample
Fig. 2. The test device and uniaxial failure sample of red sandstone.

\section{Results and Discussion}

\subsection{Strength variation characteristics}

The stress-strain curves of the uniaxial and triaxial tests are shown in Fig. 3. As seen from Fig. 3(a), C-8, C-9, and C-10 represent the dry samples and $\mathrm{H}-1, \mathrm{H}-2$, and $\mathrm{H}-3$ indicate the saturated samples, respectively. The dry and saturated samples all have experienced four stages, such as compaction, elasticity, yield and post-peak failure. The uniaxial compressive strength and the elastic modulus of the dry samples are larger than that of the saturated ones.

It can be seen from Figs. 3(b) and 3(c), the triaxial compressive strength and the elastic modulus of the dry and saturated samples all increase with increase of the confining pressure. And the post-peak behaviors gradually change from ductility to brittleness for all samples with increase of the confining pressure.

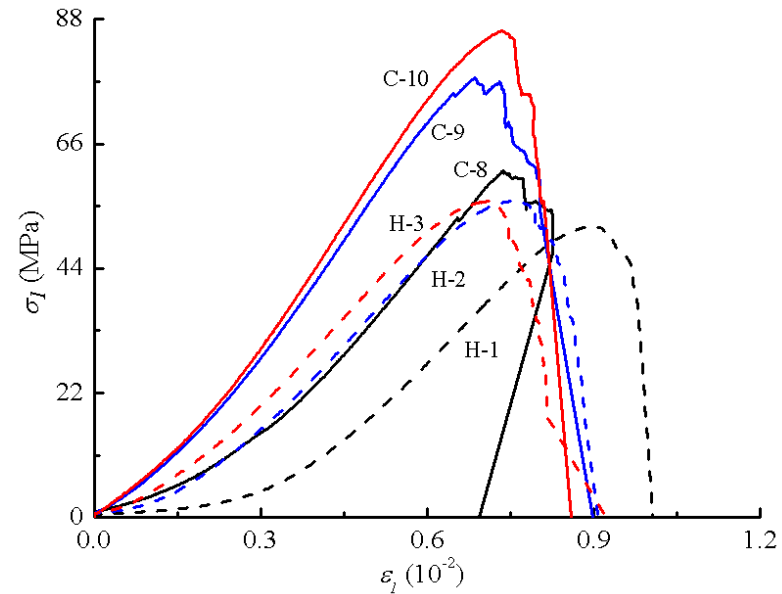

(a) Dry and saturated samples under uniaxial compressive tests.

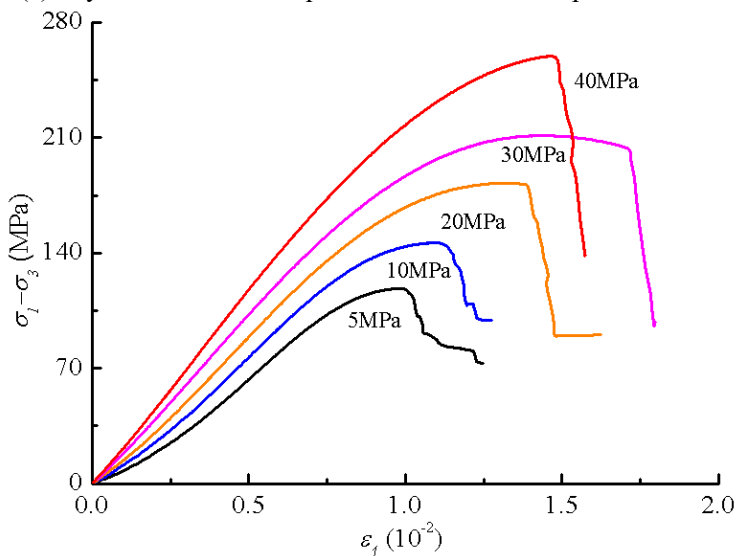

(b) Dry samples under triaxial compressive tests.

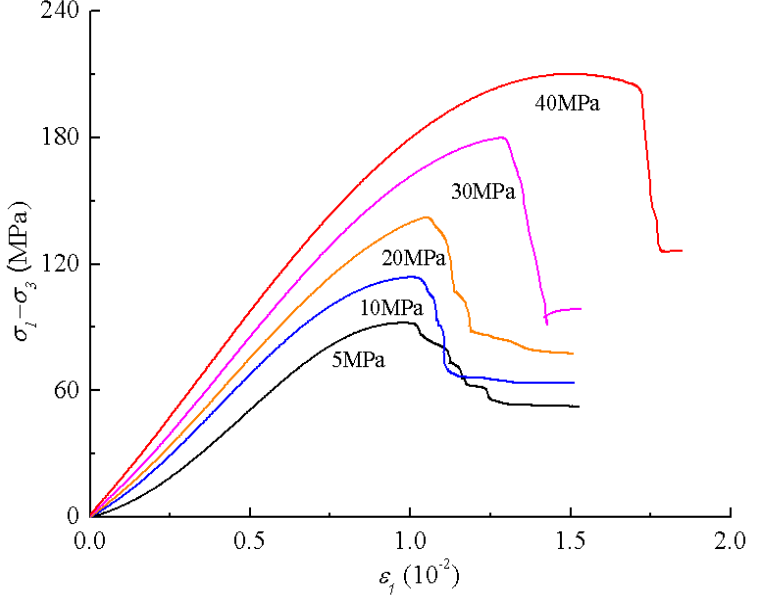

(c) Saturated samples under triaxial compressive tests.

Fig. 3. Stress-strain curves of dry and saturated red sandstone under different test conditions.

\subsection{Strength degradation characteristics}

The elasticity modulus $E$ is the slope of the approximate straight section of the stress-strain curve (30-70\% peak strength), the deformation modulus Es is the slope of the line from the origin to the peak of the stress-strain curve.

To study the influence of the saturated water on the deformation and strength characteristics of the samples, the degradation rate is defined as $\eta$ :

$\eta=\frac{f_{\mathrm{z}}-f_{\mathrm{B}}}{f_{\mathrm{z}}} \times 100 \%$

where, $f_{\mathrm{z}}$ is the strength or deformation of the dry sample. $f_{\mathrm{B}}$ is the corresponding strength and deformation of the saturated sample. When $f_{\mathrm{z}}$ is less than $f_{\mathrm{B}}$, it is called strengthening rate.

As seen from Fig. 4, that there is a close relationship between the strength degradation rate and the softening coefficient (the ratio of the saturated peak strength to the dry peak strength) and confining pressures. In general, with increase of the confining pressure, the strength degradation rate decreases and then tends to a certain value, while the softening coefficient increases and tends to another value. When the confining pressure is less than $20 \mathrm{MPa}$, the strength degradation rate decreases rapidly with increase of the confining pressure. While when the confining pressure is greater than $20 \mathrm{MPa}$, the strength degradation rate tends to be $16.50 \%$. The uniaxial compressive strength degradation rate is the largest, and the strength degradation rate of the uniaxial compressive sample is 1.92 times of that of the triaxial compressive sample under high confining pressure.

When the confining pressure is less than $20 \mathrm{MPa}$, the softening coefficient increases rapidly with increase of the confining pressure. While when the confining pressure is greater than $20 \mathrm{MPa}$, the softening coefficient tends to be 0.835 . The softening coefficient at high confining pressure is 1.23 times of that at low confining pressure, which show that the saturated water has a significant effect on the strength degradation of the red sandstone under uniaxial compressive test and the softening effect is obvious. When the confining pressure is greater than $20 \mathrm{MPa}$, the strength degradation effect and softening effect tend to a certain value 


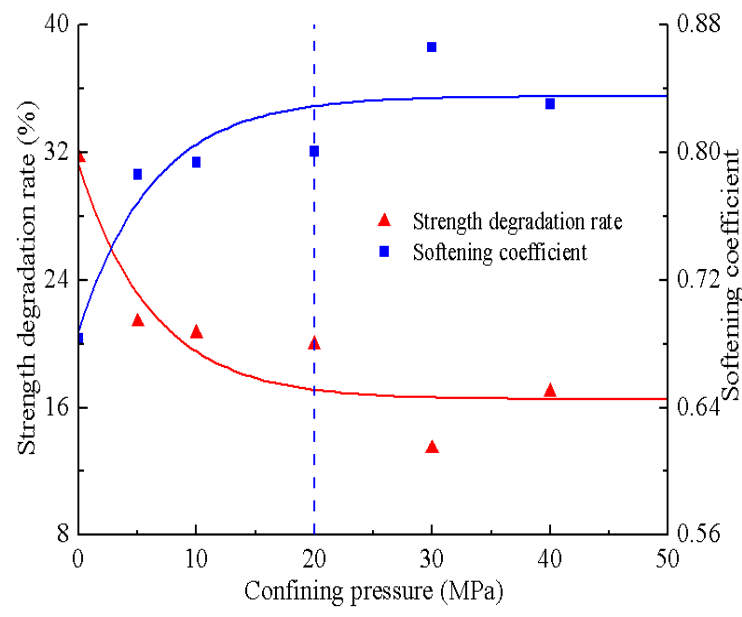

Fig. 4. The strength degradation rate and softening coefficient under different confining pressures.

As seen from Fig. 5, the confining pressure has a significant influence on the degradation rate of the elastic modulus and deformation modulus. EMDR represents elastic modulus degradation rate, DMDR represents deformation modulus degradation rate. Similarly, $20 \mathrm{MPa}$ is the turning confining pressure of the degradation rate change. When the confining pressure is less than $20 \mathrm{MPa}$, the degradation rate of the elastic and deformation modulus decreases approximately linearly with increase of the confining pressure. When the confining pressure is greater than 20 $\mathrm{MPa}$, the degradation rate of the elastic and deformation modulus fluctuates around a certain value.

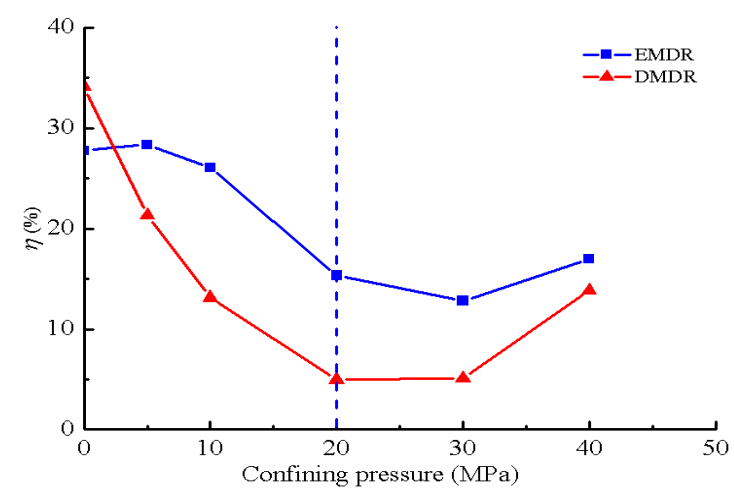

Fig. 5. Degradation rate curves of the elastic(deformation) modulus under different confining pressures.

The average value of the degradation rate of 20,30 , and $40 \mathrm{MPa}$ confining pressure is determined as the certain value. With increase of the confining pressure, the degradation rate of the elastic and deformation modulus tends to be $15.04 \%$ and $7.99 \%$, respectively. The degradation rate of the elastic and deformation modulus under uniaxial compressive test is $27.77 \%$ and $34.10 \%$, respectively. The degradation rate of elastic and deformation modulus under compressive uniaxial test is 1.85 and 4.27 times of that under the 30 and $40 \mathrm{MPa}$ confining pressures, respectively. The degradation law of the elastic and deformation modulus affected by saturated water is basically the same, but the degradation rate of the elastic modulus is greater than that of the deformation modulus.

\subsection{Polyline strength criterion}

In Fig.6, the complete fitting is that the data of the uniaxial and triaxial compressive test are all fitted, the shielding fitting is only to fit the triaxial compressive data. SCFIDS represents strength complete fitting in dry state, SSFIDS represents strength shielding fitting in dry state, SCFISS represents strength complete fitting in saturated state, and SSFISS represents strength shielding fitting in saturated state. The maximum and the minimum principal stress of the samples under dry and saturated states subjected to the compressive tests are shown in Fig. 6.

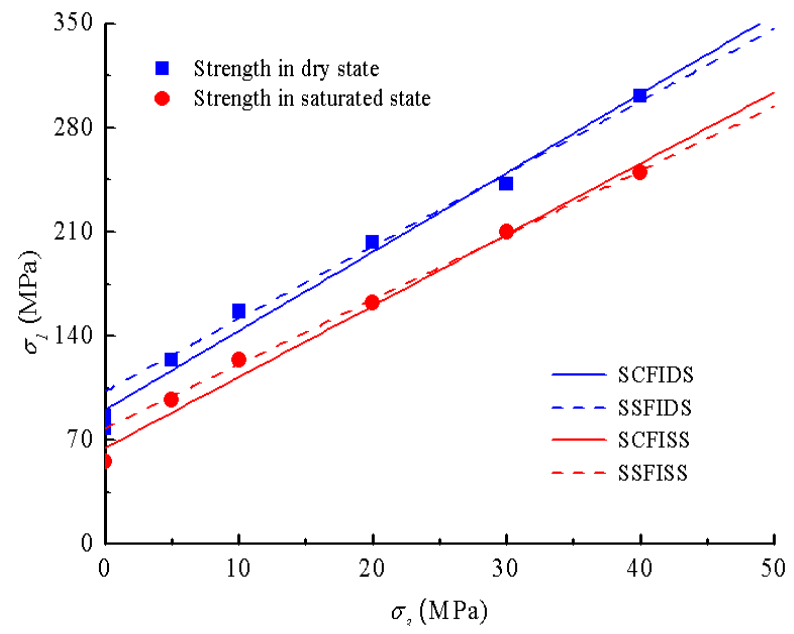

Fig. 6. Peak strength curves variation with confining pressure.

In Fig.6, the test data of the dry and saturated red sandstone are fitted with Coulomb strength criterion, respectively:

$\sigma_{1}=k \sigma_{3}+m$

where, $\sigma_{1}$ is the maximum principal stress. $\sigma_{3}$ is the minimum principal stress, $m$ is the uniaxial compressive strength of the dry and saturated samples obtained from the complete and shield fitting. $k$ is the influence coefficient of the confining pressure on the strength of the samples. In addition, the maximum and the minimum principal stress can be expressed as Eq. (3):

$\sigma_{1}=\frac{1+\sin \varphi}{1-\sin \varphi} \sigma_{3}+\frac{2 c \cos \varphi}{1-\sin \varphi}$

The internal friction angle $\varphi$ and cohesion $c$ of the dry and saturated samples can be obtained as follows:

$\varphi=\arcsin ((k-1) /(k+1))$

$c=m(1-\sin \varphi) / 2 \cos \varphi$

The calculation results of each parameter are listed in Table 1. It can be seen from Table 1 that the complete fitting considering the uniaxial compressive test data increases the internal friction angle and decreases the cohesion. The saturated water makes the strength of the red sandstone weaken, and the internal friction angle and cohesion decrease. But the decrease of the internal friction angle is smaller and the decrease of cohesion is larger. For complete and shielding fitting, the internal friction angle is reduced by $5.18 \%$ and $6.27 \%$, and the cohesion is reduced by $24.50 \%$ and $19.85 \%$, respectively. It can be seen that the effect of the saturated water on the degradation of the cohesion of the 
samples is significant, while the effect on the degradation of the internal friction angle is small.

Table 1. Strength parameters of the dry and saturated samples.

\begin{tabular}{c|c|c|c|c}
\hline Name & $k$ & $m(\mathrm{MPa})$ & $\varphi\left(^{\circ}\right)$ & $c(\mathrm{MPa})$ \\
\hline $\begin{array}{c}\text { Complete fitting } \\
\text { in dry state }\end{array}$ & 5.31 & 90.33 & 43.09 & 19.59 \\
$\begin{array}{c}\text { Complete fitting } \\
\text { in saturated state } \\
\begin{array}{c}\text { Shielding fitting } \\
\text { in dry state }\end{array}\end{array}$ & 4.78 & 64.70 & 40.86 & 14.79 \\
$\begin{array}{c}\text { Shielding fitting } \\
\text { in saturated state }\end{array}$ & 4.34 & 77.65 & 38.69 & 18.65 \\
\hline
\end{tabular}

As can be seen from Fig. 6, the complete and shielding fitting of the dry and saturated samples intersect at $30 \mathrm{MPa}$. The complete fitting is in good agreement with the experimental data from 0 to $30 \mathrm{MPa}$, and the shielding fitting agrees well with the experimental data when the confining pressure is greater than $30 \mathrm{MPa}$. As shown in Fig. 7, the new polyline strength criterion of the dry and saturated samples taking 30 $\mathrm{MPa}$ as the turning confining pressure is established.

The polyline strength criterion of the dry red sandstone is:

$\left\{\begin{array}{l}\sigma_{1}=90.33+5.31 \sigma_{3}\left(0 \leq \sigma_{3} \leq 30 \mathrm{MPa}\right) \\ \sigma_{1}=102.82+4.88 \sigma_{3}\left(30 \mathrm{MPa} \leq \sigma_{3}\right)\end{array}\right.$ is:

The polyline strength criterion of the saturated red sandstone

$$
\left\{\begin{array}{l}
\sigma_{1}=64.70+4.78 \sigma_{3}\left(0 \leq \sigma_{3} \leq 30 \mathrm{MPa}\right) \\
\sigma_{1}=77.65+4.34 \sigma_{3}\left(30 \mathrm{MPa} \leq \sigma_{3}\right)
\end{array}\right.
$$

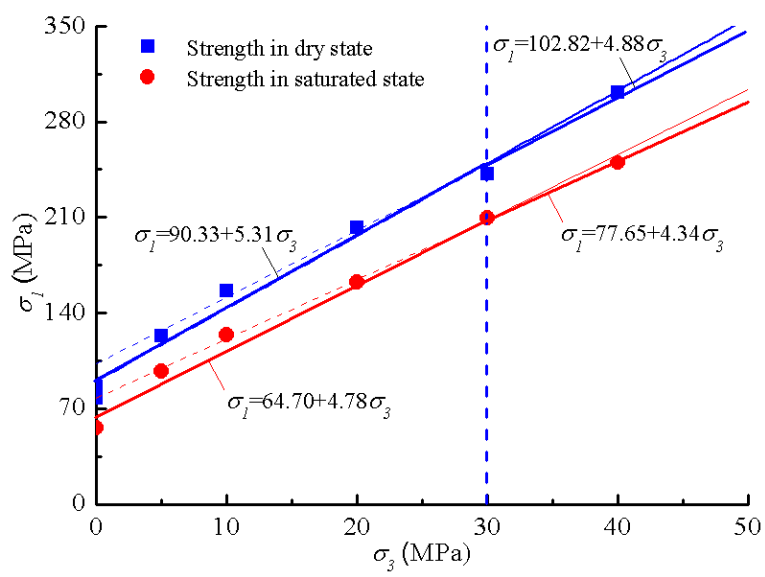

Fig. 7. The polyline strength criterion of the dry and saturated red sandstone.

\subsection{Three-dimension strength criterion}

In the three-dimension principal stress space, the strength criterion is usually expressed as a combination of the meridian and deviatoric plane functions. The straight line that three principal stresses are equal is the hydrostatic pressure axis, the plane perpendicular to the hydrostatic pressure axis is called a deviatoric plane. The distance between a point on the hydrostatic pressure axis and the coordinate origin is called hydrostatic pressure $\xi$.

$\xi=\left(\sigma_{1}+\sigma_{2}+\sigma_{3}\right) / \sqrt{3}=I_{1} / \sqrt{3}$
As shown in Fig. 10, $I_{1}=\sigma_{1}+\sigma_{2}+\sigma_{3}$ is the first invariant of the stress tensor. $r_{\sigma}$ is the distance from the failure curve on the deviatoric plane to the hydrostatic pressure axis ( $r$ is the maximum value of $r_{\sigma}$ ), and $\theta_{\sigma}$ is the Lode angle.

$r=\frac{1}{\sqrt{3}} \sqrt{\left(\sigma_{1}-\sigma_{2}\right)^{2}+\left(\sigma_{2}-\sigma_{3}\right)^{2}+\left(\sigma_{1}-\sigma_{3}\right)^{2}}=\sqrt{2 J_{2}}$

$J_{2}=\frac{1}{6}\left[\left(\sigma_{1}-\sigma_{2}\right)^{2}+\left(\sigma_{2}-\sigma_{3}\right)^{2}+\left(\sigma_{1}-\sigma_{3}\right)^{2}\right]$

$\theta_{\sigma}=\tan ^{-1}\left(\frac{1}{\sqrt{3}} \frac{2 \sigma_{2}-\sigma_{1}-\sigma_{3}}{\sigma_{1}-\sigma_{3}}\right)$

$r_{\sigma}=\sqrt{2 J_{2}} g\left(\theta_{\sigma}\right)$

where, $J_{2}$ is the second invariant of the stress deviator. Deviatoric plane function $g\left(\theta_{\sigma}\right)$ is the expression form of the strength envelope on the deviatoric plane.

Many scholars have put forward many kinds of deviatoric plane function. In this study, the William-Warnke's deviatoric plane function is used, which meets the requirement of the convexity. The specific expression is as follows.

$g\left(\theta_{\sigma}\right)=\frac{2\left(1-K^{2}\right) \cos \left(\frac{\pi}{6}-\theta_{\sigma}\right)+(2 K-1) \sqrt{4\left(1-K^{2}\right) \cos ^{2}\left(\frac{\pi}{6}-\theta_{\sigma}\right)+K(5 K-4)}}{4\left(1-K^{2}\right) \cos ^{2}\left(\frac{\pi}{6}-\theta_{\sigma}\right)+(2 K-1)^{2}}$

$K=\frac{(3-\sin \varphi)}{(3+\sin \varphi)}$

where, $\varphi$ is the internal friction angle of the sample. The internal friction angle is $43.09^{\circ}$ in the dry state and $40.86^{\circ}$ in the saturated state. The corresponding $K$ is 0.629 and 0.642 , respectively. When plotting the deviatoric plane function, the Lode angle is taken from $-30^{\circ}$ to $30^{\circ}$, and other areas are obtained according to the symmetry. The envelopes of the deviatoric plane strength of the dry and saturated samples is shown in Fig. 8.

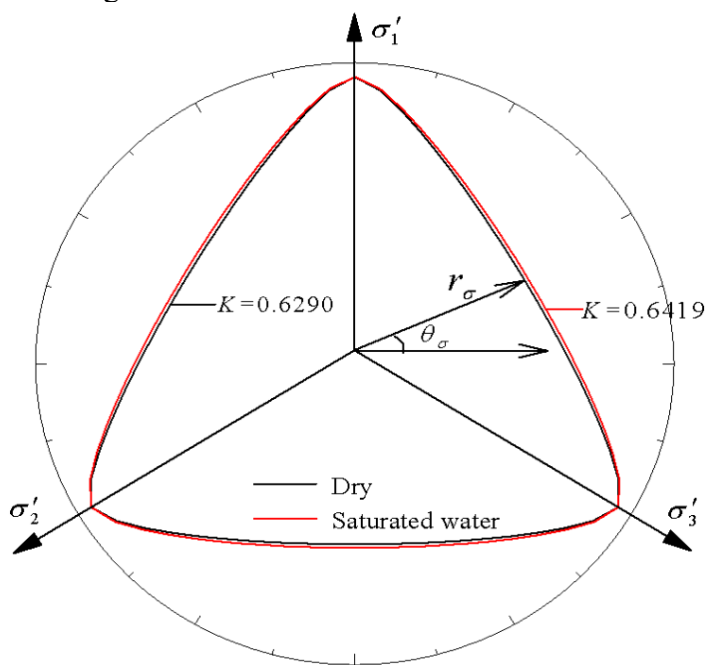

Fig. 8. The deviatoric plane function of the dry and saturated red sandstone. 
To construct the three-dimension strength criterion, the characteristics of the meridian plane strength envelope should be clarified. Based on the triaxial compressive test, these data in $I_{1} / \sqrt{3}-\sqrt{2 J_{2}}$ meridian plane are analyzed and fitted by the quadratic function. It can be seen that the fitting curves can well describe its strength law in Fig. 9. $a$ represents $\sqrt{2 J_{2}}, b$ represents $I_{1} / \sqrt{3}$. SIDS represents strength in dry state, SISS represents strength in saturated state, SFCIDS represents strength fitting curve in dry state, and SFCISS represents strength fitting curve in saturated state.

The meridian function of the dry red sandstone is as follow:

$$
\sqrt{2 J_{2}}=22.15+0.9944 \times\left(\frac{I_{1}}{\sqrt{3}}\right)-0.0006 \times\left(\frac{I_{1}}{\sqrt{3}}\right)^{2}
$$

The meridian function of the saturated red sandstone is as follows.

$$
\sqrt{2 J_{2}}=15.43+0.9910 \times\left(\frac{I_{1}}{\sqrt{3}}\right)-0.0009 \times\left(\frac{I_{1}}{\sqrt{3}}\right)^{2}
$$

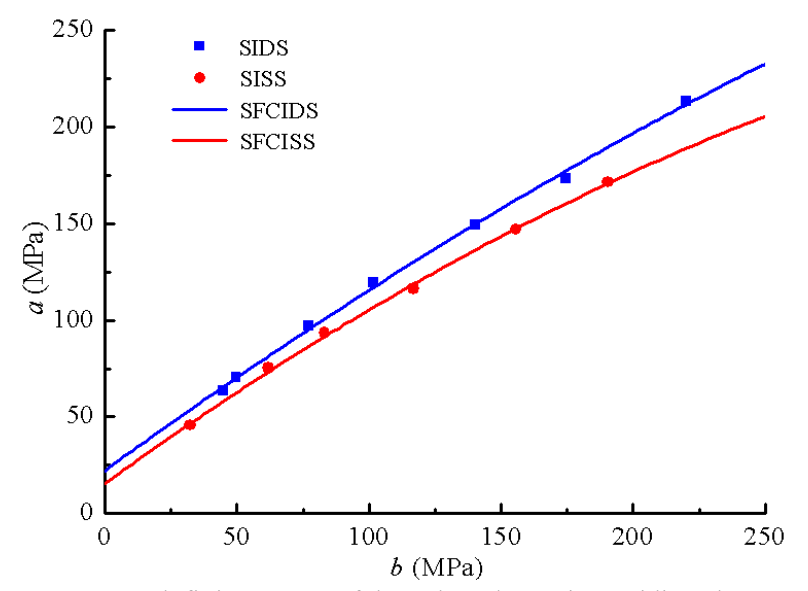

Fig. 9. Strength fitting curves of the red sandstone in meridian plane.

Combining the meridian plane function and the deviatoric plane function, the three-dimension strength surface of the dry and saturated red sandstone can be obtained, as shown in Figs. 10 and 11 . The three-dimension strength surface in the saturated state is smoother than that in the dry state. The three-dimension strength criterion of the dry red sandstone is expressed by the meridian plane Eq. (15) and the deviatoric plane Eq. (13), and the three-dimension strength criterion of the saturated red sandstone is expressed by the meridian plane Eq. (16) and the deviatoric plane Eq. (13).

When the stress state $\left(\sigma_{1}, \sigma_{2}, \sigma_{3}\right)$ of the dry and saturated red sandstone is known, $\left(\xi, \theta_{\sigma}, r_{\sigma}\right)$ can be calculated according to the above formulas, and then determining whether the rock is failure in the three-dimension stress space.

\subsection{Failure characteristics of samples}

The failure characteristics of the dry and saturated samples under uniaxial and triaxial compressive tests are shown in Fig. 12. The damage degree of the samples under the uniaxial compressive test is severe, and the brittleness is significant. In the dry state, there are many small cracks on both sides of the main fracture surface, the saturated water makes the damage degree of the samples weaken, and the small cracks disappear. Under the uniaxial and low confining pressure, the red sandstone has a large fracture angle and the multiple main fracture surfaces close to upright, which is a typical tensile failure mode. Figs.12(a) and 12(b) show that the typical shear failure with a single fracture surface occurs when the confining pressure of the red sandstone is greater than $10 \mathrm{MPa}$ in the dry state and greater than $5 \mathrm{MPa}$ in the saturated state.

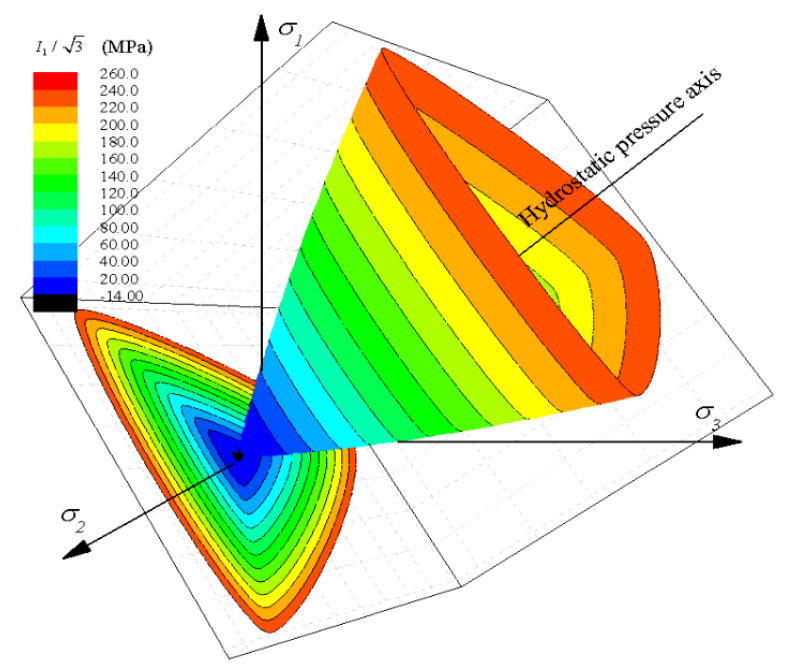

Fig. 10. The three-dimension strength surface of the dry red sandstone.

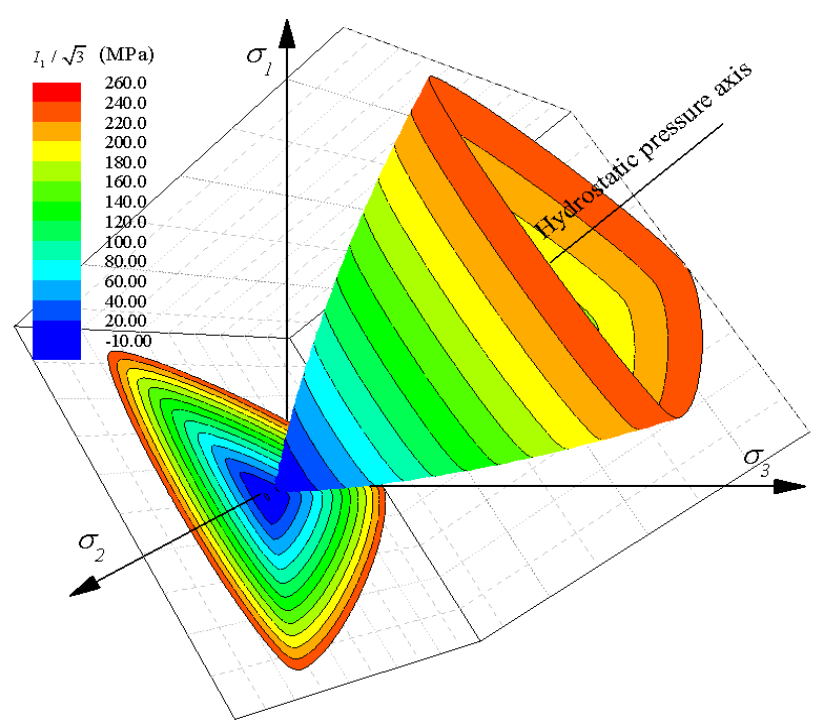

Fig. 11. The three-dimension strength surface of the saturated red sandstone.

In general, the fracture angle in the dry state is larger than that in the saturated state, and the fracture angle decreases obviously in the saturated state with increase of the confining pressure. According to the failure morphology analysis in Fig. 12 , the dry red sandstone is more brittle and the saturated water reduces its the brittleness. Under the uniaxial and low confining pressure, the confining pressure constraint is lower, and the internal damage distribution zone is wide. Many microcracks gather and develop in many directions, form many main fracture surfaces, and the failure degree is serious. When the confining pressure is higher, the confining pressure constraint is larger, the internal damage is concentrated. The microcracks gather and develop in a single direction, form a single fracture surface, and the failure is concentrated.
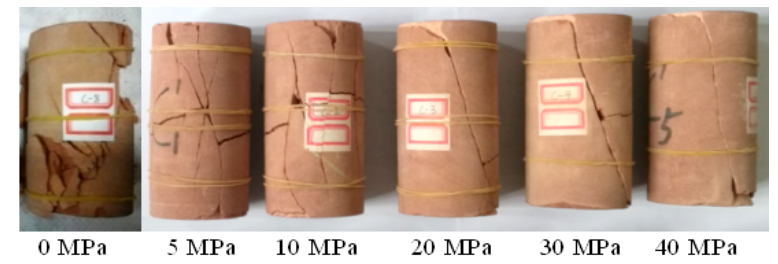

(a) In dry state 


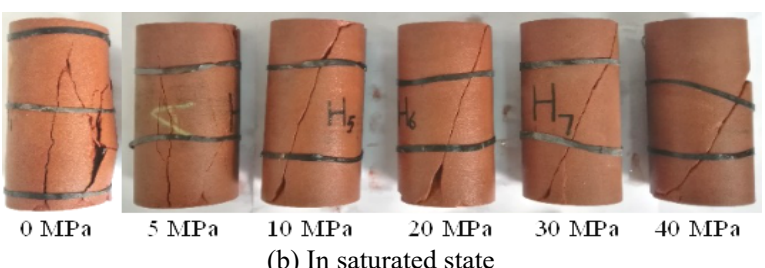

Fig. 12. Failure samples of red sandstone under uiaxial and triaxial compressive tests.

\section{Conclusions}

Through the uniaxial and triaxial compressive tests on the dry and saturated red sandstone, the influences of the saturated water on the strength and deformation of the red sandstone were obtained, and the polyline and threedimension strength criteria were proposed. The main conclusions are as follows.

(1) The saturated water has a significant effect on the strength degradation of the red sandstone under the uniaxial compressive tests, and the softening effect is obvious. When the confining pressure is greater than $20 \mathrm{MPa}$, the strength degradation rate and softening coefficient tend to a certain value. The degradation rate of the uniaxial compressive strength is 1.92 times of that of the triaxial compressive strength. The softening coefficient under high confining pressure is 1.23 times of that under the uniaxial compressive tests.

(2) When the confining pressure is less than $20 \mathrm{MPa}$, the degradation rate of the elastic and deformation modulus decreases linearly with increase of the confining pressure. And when the confining pressure is greater than $20 \mathrm{MPa}$, the degradation rate of the elastic and deformation modulus tend to be $15.04 \%$ and $7.99 \%$, respectively. The effect of the saturated water on the degradation of the elastic modulus is greater than that of the deformation modulus.

(3) According to the complete fitting and shielding fitting, a polyline strength criterion taking $30 \mathrm{MPa}$ as the turning confining pressure was established. Combining the quadratic function of the strength of the red sandstone in the meridian plane and the specific deviatoric William-Warnke function, a three-dimension strength criterion of the dry and saturated red sandstone was constructed.

(4) The internal damage of the red sandstone in the uniaxial compressive tests is serious. Many microcracks gather and develop along many directions, form many main fracture surfaces, and the degree of the failure is serious. The development of the damage is concentrated in the triaxial compressive tests, the microcracks gather and develop in a single direction, form a single main fracture surface. The saturated water reduces the brittleness of the red sandstone, makes the fracture surface regular, and the fracture angle is smaller than that in the dry state.

The polyline and three-dimension strength criteria of the dry and saturated red sandstone proposed in this study are simple and easy to use, and can better predict the strength of the intact rock mass in underground engineering. The surrounding rock in the actual engineering often has many joints and cracks, which weaken the integrity of the rock mass and affect its strength. Therefore, the characteristics of the joints and cracks will be introduced into the polyline strength criterion to further expand the scope of application of the polyline strength criterion proposed in the further study.

\section{Acknowledgements}

This work was financially supported by the National Natural Science Foundation of China (U1810203; U1604142), the Young Excellent Teacher Project of Henan Polytechnic University(2016XQG-10).

This is an Open Access article distributed under the terms of the Creative Commons Attribution License

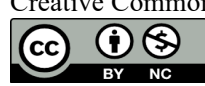

\section{References}

1. Wang, S. R., Hagan, P., Li, Y. C., Zhang, C., G., Liu, X., L., "Experimental study on deformation and strength characteristics of sandstone with different water contents", Journal of Engineering Science and Technology Review, 10(4), 2017, pp. 199-203.

2. Deng, H. F., Zhi, Y. Y., Duan, L. L., Pan, D., Li, J. L., "Mechanical properties of sandstone and damage evolution of microstructure under water-rock interaction", Rock and Soil Mechanics, 40(9), 2019, pp. 3447-3456.

3. Jiang, Q., Deng, H. F., Li, J. L., Luo, Z. S., Assefa, E., Fang, J. C., Xiao, Y., "The degradation effect and mechanism by water-rock interaction in the layered sandstone in the Three Gorges reservoir area", Arabian Journal of Geosciences, 12, 2019, pp. 722.

4. Zhu, J., Deng, J., H., Huang, Y., M., Yu, Z. Q., "Experimental study on the characteristic strength of saturated marble", Chinese Journal of Rock Mechanics and Engineering, 38(6), 2019, pp. 1129-1138.

5. Mei, J., Yang, L., Sheng, X. C., Song, G. X., Yang, W. M., Zhang, B., "Time-dependent propagation of 3-D cracks in rocks under hydromechanical coupling", Rock Mechanics and Rock Engineering, DOI:10.1007/s00603-019-02020-2.

6. Zhou, C. Y., Su, D. L., Qiu, X. L., Yang, X., Liu, Z., "Experimental study of cracked soft rock with hydro-mechanical coupling effect", ACTA Scientiarum Naturalium Universitatis Sunyatseni, 58(6), 2019 , pp. 35-44.

7. Xie, X. S., Chen, H. S., Xiao, X. H., Wang, J., Zhou, J. W., "Microstructural characteristics and softening mechanism of red-bed soft rock under water-rock interaction condition", Journal of Engineering Geology, 27(5), 2019, pp. 966-972.
8. Xu, J., Zhang, J. S., Liu, T. Y., "Mesoscopic Weakening Feature of Marble During Water Rock Interaction", Geotechnical and Geological Engineering, 37, 2019, pp. 121-128.

9. Yang, X. J., Wang, J. M., Zhu, C., He, M. C., Gao, Y., "Effect of wetting and drying cycles on microstructure of rock based on SEM", Environmental Earth Sciences, 78(6), 2019, Article ID 183: 1-10.

10. Wong, L. N. Y., Maruvanchery, V., Liu, G., "Water effects on rock strength and stiffness degradation", Acta Geotechnica, 11, 2016, pp. 713-737.

11. Cai, X., Zhou, Z. L., Liu, K. W., Du, X. M., Zang, H. Z., "Waterweakening effects on the mechanical behavior of different rock types: phenomena and mechanisms", Applied Scieneces-Basel, 9(20), 2019, Article ID 4450: 1-18.

12. Liu, Z., He, X. F., Fan, J., Zhou, C. Y., "Study on the softening mechanism and control of red-bed soft rock under seawater conditions", Journal of Marine Science and Engineering, 7(7), 2019, Article ID 235: 1-16.

13. Hashiba, K., Fukui, K., "Index of Loading-Rate Dependency of Rock Strength", Rock Mechanics and Rock Engineering, 48, 2015, pp. 859-865.

14. Zhang, X. L., Han, Z. F., Han, W. S., He, M. C., Tao, Z. G., Gu, M., "Water absorption and strength softening law of chlorite amphibolite in Nanfen open-pit mine", Journal of China Coal Society, 43(9), 2018, pp. 2452-2460.

15. Zhu, Q. Z., "A New Rock Strength Criterion from Microcracking Mechanisms Which Provides Theoretical Evidence of Hybrid Failure', Rock Mechanics and Rock Engineering, 50, 2017, pp. 341352. 
16. He, W. H., Hayatdavoudi, A., Shi, H. Z., Sawant, K., Huang, P., P., "A Preliminary Fractal Interpretation of Effects of Grain Size and Grain Shape on Rock Strength", Rock Mechanics and Rock Engineering, 52, 2019, pp. 1745-1765.

17. Wang, S. R., Hagan, P., Zhao, Y. H., Chang, X., Song, K. I., Zou, Z. $S$., "The effect of confining pressure and water content on energy evolution characteristics of sandstone under stepwise loading and unloading", Advances in Civil Engineering, Vol. 2018, Article ID 4751612: 1-8.

18. Wang, S. R., Zhao, Y. H., Zou, Z. S., Jia, H. H., "Experimental research on energy release characteristics of water-bearing sandstone alongshore wharf", Polish Maritime Research, 24, 2017, pp. 147153.

19. Cui, J., Jiang, Q., Li, S. J., Feng, X. T., Zhang, Y. L., Shi, Y. E., "Numerical Study of Anisotropic Weakening Mechanism and Degree of Non-Persistent Open Joint Set on Rock Strength with Particle Flow Code", KSCE Journal of Civil Engineering, 24(2), 2020, pp. 988-1009.

20. Zhou, J. X., Zhou, Y., Gao, Y. T, "Effect Mechanism of Fractures on the Mechanics Characteristics of Jointed Rock Mass Under Compression", Arabian Journal for Science and Engineering, 43, 2018, pp. 3659-3671.
21. Liang, M., Mohamad, E. T., Faradonbeh, R. S., Armaghani, D. J., Ghoraba, S., "Rock strength assessment based on regression tree technique", Engineering with Computers, 32, 2016, pp. 343-354.

22. Li, D. Y., Wang, W. J., "Quantitative analysis of the influence of saturation on rock strength reduction considering the distribution of water", Geomechanics and Geophysics for Geo-Energy and GeoResources, 5, 2019, pp. 197-207.

23. Mohamad, E. T., Armaghani, D. J., Momeni, E., Yazdavar, A. H., Ebrahimi, M., "Rock strength estimation: a PSO-based BP approach", Neural Computing \& Applications, 30, 2018, pp. 16351646.

24. Li, W., Tan, Z. Y., "Research on Rock Strength Prediction Based on Least Squares Support Vector Machine", Geotechnical and Geological Engineering, 35, 2017, pp. 385-393.

25. Zou, J. P., Jiao, Y. Y., "Experimental Study of Multiple-Step Triaxial Compression for the Determination of Rock Strength Parameters", Rock Mechanics and Rock Engineering, 52, 2019, pp. 455-463.

26. Zhang, Q., Li, C., Quan, X. W., Wang, Y. N., Yu, L. Y., Jiang, B. S., "New true-triaxial rock strength criteria considering intrinsic material characteristics", Acta Mechanica Sinica, 34(1), 2018, pp. 130-142. 